\title{
Desorption of aqueous salt solution in minichannels
}

\author{
S. Y. Misyura ${ }^{1 \mathrm{a}}$, V. S. Morozov ${ }^{1}$ \\ ${ }^{1}$ Institute of Thermophysics Siberian Branch, Russian Academy of Sciences, Lavrentiev Ave. 1, Novosibirsk, \\ 630090, Russia
}

\begin{abstract}
This work is devoted the research for aqueous solution desorption of salt $\mathrm{LiBr}$ in minichannels with different wall thicknesses. There is a change in time of the physical properties of the solution and a change of equilibrium conditions and there is a third solid phase. Under identical liquid flow rates and the identical heat fluxes a variation in wall thickness leads to a change in desorption mode. The emulsion mode with wall thickness of $\delta=3 \mathrm{~mm}$ was not observed due to strong cooling of inner glass surface.
\end{abstract}

\section{Introduction}

To date, the task of mapping modes for iso-thermal flows in channels is practically solved. A map mode drawing for non-isothermal flows is facing great difficulties even in formation of determining criteria. One and the same criterion for different modes can lead to contradictory conclusions. For example, a ten-fold reduction in heat transfer may be due to thickening of liquid film and suppression of nucleate boiling, and may be also associated with a boiling crisis (local separation of liquid from the wall). Often the experiment does not allow us to identify factors of multiple changes in intensity of heat transfer. Experimental and theoretical complexity significantly increase when there are nonisothermal conditions and also due to desorption of solutions in the channels. As there is a change in time of physical properties of the solution and change of conditions of equilibrium and there is third solid phase. This work involves the aqueous solution desorption of salt $\mathrm{LiBr}$ in minichannels with different wall thicknesses.

\section{Experimental data}

The experimental setup is shown in [1]. In the horizontal cylindrical channel (the quartz glass thickness was $3 \mathrm{~mm}$ in diameter) was fed an aqueous solution of lithium bromide. The flow rate was constant. The heating of the outer glass wall produced by a constant heat flux. LiBr aqueous solution with a salt concentration of about $50 \%$ was fed to the channel. Two-phase mixture (steam-water) was created as a result of heating the wall. The wall temperature increases from $100{ }^{\circ} \mathrm{C}$ (at the beginning of the channel) to $150{ }^{\circ} \mathrm{C}$ (at the end of the channel). There were the following desorption modes: 1) the bubble mode (Fig. 1 (a)); 2) the plug mode; 3) the laminated mode; 4) the oscillating laminated

a Corresponding author: misyura@itp.nsc.ru 
mode; 5) the emulsion mode (Fig. 1 (b)); 6) the flow choking mode with crystalline hydrate. The emulsion regime was extremely unstable and there were strong fluctuations in flow rate. Heat and mass transfer efficiency is determined by desorption of fine droplets in the core stream for emulsion regime and due to impact of droplets on the wall surface. The evaporation of droplets in the flow of the oncoming air investigated in [2]. The behavior of aqueous LiBr discussed in [3, 4]. Evaporation of liquid was investigated in [5-15]. The explosive mixture of liquid nitrogen jet with water and evaporation of fine droplets is given in [16-17]. To evaluate the intensity of the phase transition (liquid - (steam + salt)) in [1] introduced parameter - desorption efficiency $\left(\Delta C=C_{2}-C_{l}\right.$, where $C_{l}$ is the concentration of the salt at the input of the channel, $C_{2}$ - at the exit of the channel). Desorption efficiency has allowed to compare different flow regimes. The higher $\Delta C$, the higher the efficiency of desorption. The efficiency is a function of $\Delta \mathrm{C}=f\left(\alpha, S, \Delta T, r_{d} \ldots\right)$, were $r_{d}$ is specific heat of desorption, $\alpha$ is the heat transfer coefficient, $S$ is the total area of the liquid-vapor interface. It is shown [1] that conjugate effect of the wall increases at high heat fluxes. During emulsion desorption mode (high overheating) the role of accounting in the wall thickness increases substantially. Experiments for quartz tubes with thickness of $\delta=1 ; 4 \mathrm{~mm}$ were carried out.

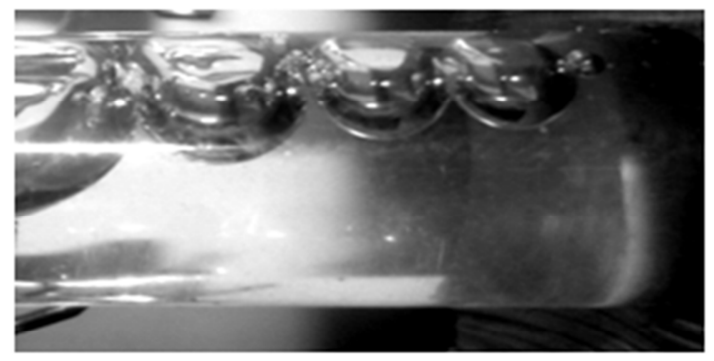

Fig. 1(a)

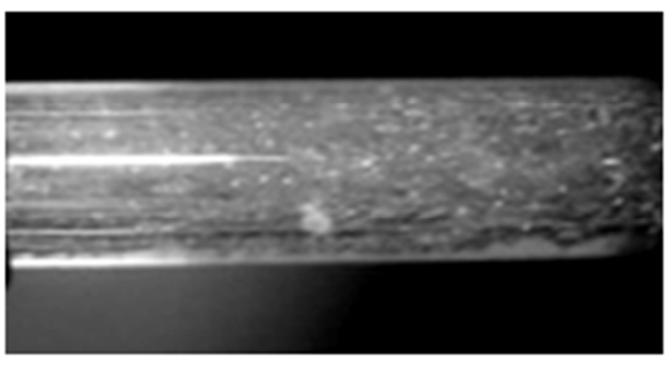

Fig. 1(b)

The data for $\Delta \mathrm{C}$ are shown in Table. Under the identical liquid flow rates and the identical heat fluxes a variation in the wall thickness leads to a change in desorption mode. The emulsion mode with wall thickness of $\delta=3 \mathrm{~mm}$ was not observed due to strong cooling of inner glass surface. As a result, there was slug mode with lower value of $\Delta \mathrm{C}$.

Table 1. The effect of the wall thickness on desorption.

\begin{tabular}{|c|c|c|}
\hline The wall thickness $\boldsymbol{\delta}$, мм & $\mathbf{1}$ & $\mathbf{4}$ \\
\hline The flow regime & Emulsion & Slug \\
\hline The efficiency of desorption $\Delta C, \%$ & 11,5 & 2.5 \\
\hline
\end{tabular}

Thus, at high minichannel overheating the effect of wall properties (thickness, type of material) can lead to a change in desorption mode and intensity of heat and mass transfer.

\section{Acknowledgements}

This work was supported by grants of Russian Science Foundation (Project № 15-19-10025).

\section{References}

[1] V.E. Nakoryakov, S.Ya. Misyura, S.L. Elistratov, R.A. Dekhtyar, J. Engineering Thermophysics 23 (4) 257-263 (2014). 
[2] V.I. Terekhov, N.E. Shishkin, Technical Physics Letters 38 (1) 51-57 (2012).

[3] V.E. Nakoryakov, N.S. Bufetov, R.A. Dekhtyar, J. Appl. Mech. \& Tech. Phys. 45 (2) 276-280 (2004).

[4] V.E. Nakoryakov, N.S. Bufetov, N.I. Grigoryeva, R.A. Dekhtyar, Journal of Applied Mechanics and Technical Physics 44 (2) 101-108 (2003).

[5] V.E. Nakoryakov, S.Y. Misyura, S.L. Elistratov, J. Engineering Thermophysics 20 (4) 1-6 (2011).

[6] A.N. Pavlenko, V.E. Zhukov, N.I. Pecherkin, V.Yu. Chekhovich, O.A. Volodin, A. Shilkin, C. Grossmann, AIChE J. 60 (2) 690-705 (2014).

[7] A.N. Pavlenko, A.A. Tairov, V.E. Zhukov, A.A. Levin, A.N. Tsoi, J. Engineering Thermophysics 20 (4) 1-27 (2011).

[8] M.V. Bartashevich, O.A. Kabov, V.V. Kuznetsov, Fluid Dynamics 45 (6) 924-929 (2010).

[9] D.V. Feoktistov, G.V. Kuznetsov, E.G. Orlova, EPJ Web of Conferences 76012039 1-8 (2014).

[10] D.V. Feoktistov, K.A. Batischeva, E.G. Orlova, MATEC Web of Conferences 1901001 1-4 (2014).

[11] D.V. Feoktistov, I.A. Afanasyev, E.G. Orlova, EPJ Web of Conferences 8201054 1-5 (2015).

[12] V.E. Nakoryakov, S.Y. Misyura, Doklady Physics 59 (10) 441-445 (2014).

[13] S.Ya. Misyura, Int. J. Thermal Sci. 92 34-43 (2015).

[14] S.Ya. Misyura, Int. J. Heat Mass Transfer 71 197-205 (2014).

[15] D.V. Feoktistov, E.G. Orlova, G.V. Kuznetsov, EPJ Web of Conferences 8201053 1-5 (2015).

[16] V.E. Nakoryakov, A.N. Tsoi, I.V. Mezentsev, A.V. Meleshkin, J. Engineering Thermophysics 23 (1) 1-8 (2014).

[17] V.E. Nakoryakov, A.N. Tsoi, I.V. Mezentsev, A.V. Meleshkin, Thermophys. and Aeromech. 21 (3) 279-284 (2014). 